\title{
Late miscarriage caused by Serratia marcescens: a rare but dire disease in pregnancy
}

\author{
Emídio Vale-Fernandes, ${ }^{1}$ Marina Moucho, ${ }^{2}$ Otília Brandão, ${ }^{3}$ Nuno Montenegro ${ }^{2,4,5}$
}

'Department of Obstetrics and Gynaecology, Hospital de Braga, Braga, Portugal ${ }^{2}$ Department of Obstetrics and Gynaecology, Centro Hospitalar de São João, EPE, Porto, Portugal

${ }^{3}$ Department of Pathology, Centro Hospitalar de São João, EPE, Porto, Portugal ${ }^{4}$ Faculdade de Medicina da Universidade do Porto, Porto, Portugal

${ }^{5}$ EPI Unit, ISPUP, Porto, Portugal

\section{Correspondence to}

Dr Emídio Vale-Fernandes, emidio.vale.fernandes@gmail. com

Accepted 1 May 2015

\section{DESCRIPTION}

We describe the case of a previously healthy 31-year-old pregnant woman at 15 weeks gestation, gravida 6 , para 2, abortion 3, admitted in the emergency ward with the symptoms of hyperthermia, hemicranial headache, nausea, vomiting and diarrhoea. There were no symptoms related to her pregnancy. Owing to worsening of symptoms, she was admitted for further evaluation, especially to rule out Listeria monocytogenes. The patient was started on antibiotics-ceftriaxone and ampicillin. A lumbar puncture was performed and cytochemical and bacteriological examination and PCR for Listeria was negative, septic screening with urine culture was negative and blood cultures in febrile peak were positive for Serratia marcescens, sensitive to the prescribed antibiotics. The serological status for TORCH infections (toxoplasmosis, other (syphilis, varicella-zoster, parvovirus B19), rubella,

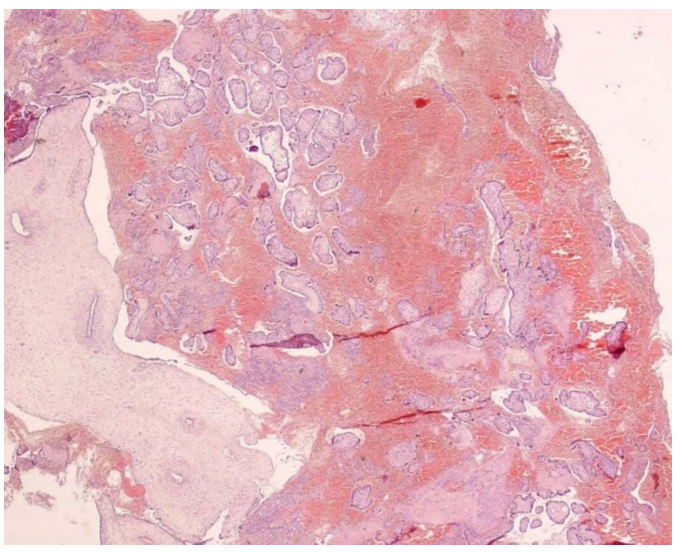

Figure 1 Microscopic findings of the placenta showing haemorrhagic areas (H\&E staining, $\times 20$ ). cytomegalovirus and herpes) was unremarkable. The laboratory tests showed leukopenia, thrombocytopenia and lymphopenia ( $91 \%$ neutrophils). During hospitalisation, the patient improved clinically with sustained non-feverish. On the eighth day of hospitalisation, she started having pelvic pain and brown odourless vaginal discharge. Cervical exudate was collected for microbiological examination, which was also positive for S. marcescens. On the 10th day of hospitalisation, the patient miscarried spontaneously. Macroscopic and histological examination of the placenta showed the chorioamnion served as a site for persistent infection in this patient (figures 1-3). The patient was discharged on the 12th day of hospitalisation, asymptomatic and treated with ceftriaxone, to complete treatment until day 14 . The follow-up consultation (6 weeks after the miscarriage) did not reveal any clinical or obstetric abnormalities.

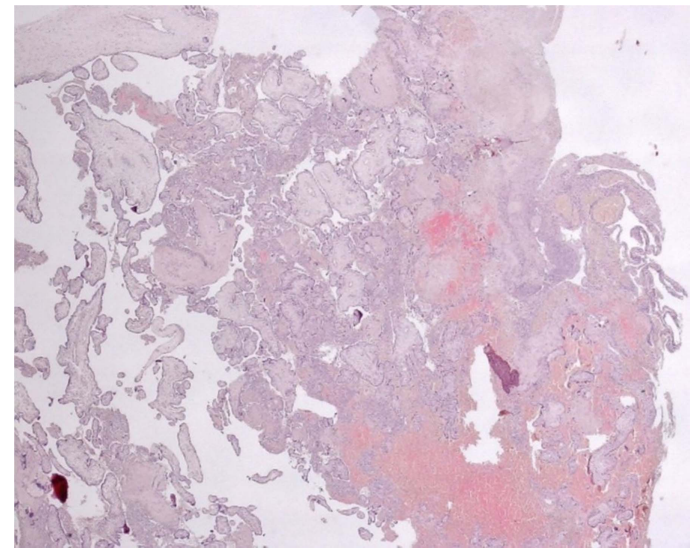

Figure 3 Microscopic findings of the basal plate of the placenta with more severe inflammatory lesions, namely, necrotising deciduitis (H\&E staining, $\times 20$ ).
To cite: Vale-Fernandes $\mathrm{E}$, Moucho M, Brandão O, et al. BMJ Case Rep Published online: [please include Day Month Year] doi:10.1136/bcr-2015210586
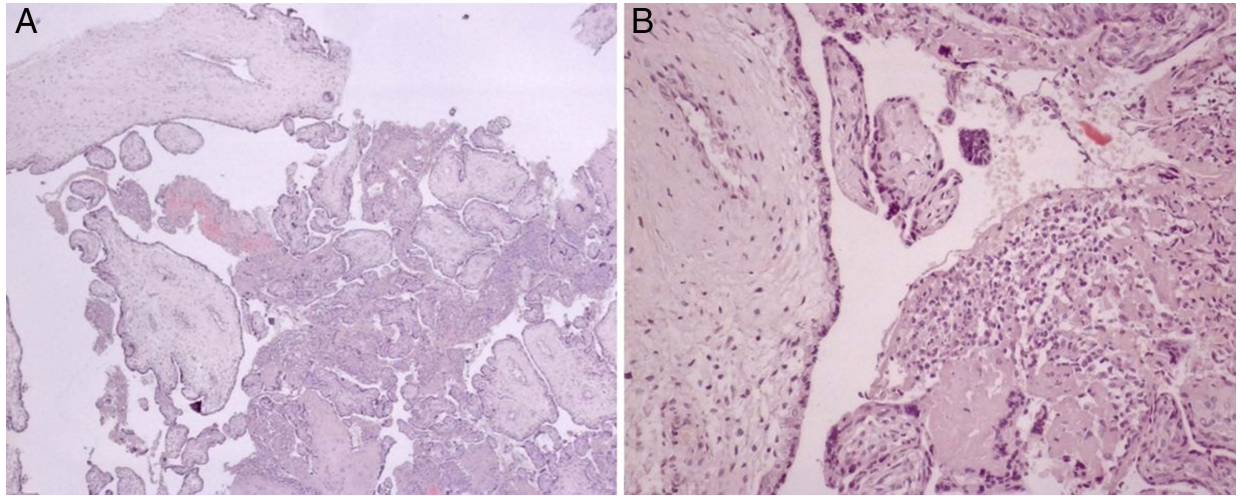

Figure 2 Microscopic findings of the placental membranes (H\&E staining) ((A) Placental membranes with acute and chronic inflammatory cells. Parenchyma with several stem villi presenting also with light inflammation. Intense acute intervillositis with perivillous fibrin deposition $(\times 40)$. (B) Vasculitis lesions $(\times 400)$ ). 


\section{Learning points}

- Chorioamnionitis, or intra-amniotic infection, is an acute inflammation of the membranes during pregnancy, typically due to ascending polymicrobial bacterial infection in the setting of membrane rupture. Only rarely is haematogenous spread implicated in chorioamnionitis, as occurs with Listeria monocytogenes. Overall, 1-4\% of all births are complicated by chorioamnionitis. ${ }^{1}$

- Several serratia spp are widely distributed in nature: in water, fruits and vegetables. Serratia marcescens is the main species isolated in hospitals. This pathogen can be responsible for nosocomial infection, mostly in immunocompromised hosts, and serratia septicaemia is a rare but dire disease in pregnancy. ${ }^{2} 3$

- S. marcescens was reported as a cause of persistent chorioamnionitis and subsequent miscarriage in only three non-immunocompromised hosts. ${ }^{2}{ }^{3}$ Our case is the fourth.
Acknowledgements The authors would like to thank the Departments of Infectious Diseases, Obstetrics and Gynaecology, Microbiology and Pathology (Centro Hospitalar de São João, EPE) for collaborating.

Contributors EV-F, MM and NM evaluated the patient in inpatient clinic. EV-F followed the patient in outpatient clinic. OB performed the histological examination. EV-F collected the data and wrote the manuscript. All the authors were involved in the conception of the work and revised it critically for important intellectual content. The authors approved the final version to be submitted/published.

Competing interests None declared.

Patient consent Obtained.

Provenance and peer review Not commissioned; externally peer reviewed.

\section{REFERENCES}

1 Tita AT, Andrews WW. Diagnosis and management of clinical chorioamnionitis. Clin Perinatol 2010;37:339-54.

2 Prosser BJ, Horton J. A rare case of serratia sepsis and spontaneous abortion. N Engl J Med 2003:348:668-9.

3 Shimizu S, Kojima H, Yoshida C, et al. Chorioamnionitis caused by Serratia marcescens in a non-immunocompromised host. J Clin Pathol 2003;56:871-2.

Copyright 2015 BMJ Publishing Group. All rights reserved. For permission to reuse any of this content visit http://group.bmj.com/group/rights-licensing/permissions.

BMJ Case Report Fellows may re-use this article for personal use and teaching without any further permission.

Become a Fellow of BMJ Case Reports today and you can:

- Submit as many cases as you like

- Enjoy fast sympathetic peer review and rapid publication of accepted articles

- Access all the published articles

- Re-use any of the published material for personal use and teaching without further permission

For information on Institutional Fellowships contact consortiasales@bmjgroup.com

Visit casereports.bmj.com for more articles like this and to become a Fellow 